\title{
MICROSTRUCTURE EVOLUTION AND MECHANICAL PROPERTIES OF UNDERWATER DRY WELDED METAL OF HIGH STRENGTH STEEL Q690E UNDER DIFFERENT WATER DEPTHS
}

\author{
Kun Sun ${ }^{\mathrm{a}, \mathrm{b}}$ \\ $\mathrm{Yu} \mathrm{Hu}{ }^{\mathrm{c}}$ \\ Yonghua Shi ${ }^{\mathrm{a}, \mathrm{b}}$ \\ Baoyi Liao $^{\mathrm{a}, \mathrm{b}}$ \\ a School of Mechanical and Automotive Engineering, South China University of Technology, Guangzhou \\ 510640, China \\ b Guangdong Provincial Engineering Research Center for Special Welding Technology and Equipment, \\ South China University of Technology, Guangzhou 510640, China \\ c School of Mechatronic Engineering and Automation, Foshan University, Foshan 528000, China
}

ABSTRACT

\begin{abstract}
Q690E high strength low alloy (HSLA) steel has been intensively applied in maritime engineering. Also, the underwater dry welding (UDW) technique has been widely used to repair important offshore facilities. In this paper, joints of Q690E steel were fabricated through single-pass underwater dry welding at three pressures $(0,0.2$, and $0.4 \mathrm{MPa})$. To study the effect of the pressure on the microstructure and mechanical properties of the UDW joint, an optical microscope $(O M)$ and scanning electron microscope (SEM) were used to observe the microstructure and fracture morphology of the welded joints. The electron backscattered diffraction (EBSD) technique was used to analyse the crystallographic features and the crystallographic grain size of the ferrites. The proportion of acicular ferrite (AF) in the UDW joints and the density of low-angle boundaries increase dramatically with the increasing depth of water. The weld metal of UDW-40 shows higher strength because more fine ferrites and low-angle boundaries within UDW-40 impede the dislocation movement.
\end{abstract}

Keywords: underwater dry welding, high strength low alloy steel, water depth, microstructural evolution, mechanical property

\section{INTRODUCTION}

Underwater welding is used to repair and maintain offshore structures, such as submarine pipelines, offshore platforms, and watercraft $[1,2]$. Underwater welding can be divided into dry and wet underwater welding $[3,4]$ and three different methods, underwater wet welding (UWW), underwater dry welding (UDW), and underwater local cavity welding (ULCW) [1,3]. Each of these methods has different characteristics. The UDW process is conducted in a large dry chamber, which could minimise the disadvantageous influence of water because the seawater in the chamber will be exhausted by the filled gas [1]. Thus, UDW can obtain better-welded joints than the other two methods. The whole UWW process is conducted in an aqueous environment, which results in a high cooling rate and the formation of porosity and cracks within welds. Compared to UDW and
ULCW, UWW is more effective, efficient, and economical and it has freedom of movement [4]. ULCW can obtain a stable welding process and improve the welding quality because of the shielding effectiveness of the small dry chamber filling gas $[1,5]$. The cooling rate of ULCW is also high. Both ULCW and UWW can result in a high hydrogen concentration of the weld metal because of the water vapour surrounding the welding arc [6].

High strength low alloy (HSLA) steel has good weldability, excellent ductility and low-temperature toughness. Thus, HSLA is widely applied in maritime engineering. The soft heat-affected zone (HAZ) in traditional arc-welded HSLA joints generally reduces the strength of the weldment $[7,8]$. The soft HAZ is caused by the slow cooling rate and the high welding heat input [7]. The low impact toughness of HAZ, especially inter-critically reheated coarse-grained HAZ, could harm the mechanical properties of the whole 
HSLA welds [9]. The martensite-austenite constituents (M-A) and bainitic microstructure have an important effect on the impact property of the HAZ [10]. The high-carbon martensite is more deleterious for these properties when compared with retained austenite. Also, the high heat input and the low cooling rate of welds could increase the cellular dendritic cell spacing and the size of the acicular ferrite laths, and reduce the acicular ferrite (AF) content [11]. The increasing cooling rate could increase the martensite, which harms the mechanical properties of HSLA welds. During underwater HSLA welding processing, the aqueous environment generates some essential problems. Jacek Tomków reported that the underwater wetwelded HSLA (S460N steel) joint is characterised by a high susceptibility to cold cracking $[6,12]$. Hao Chen et al. [13] reported that the diffusible hydrogen content in underwater wet welds significantly increased with the increasing water depth because of the high hydrogen partial pressure and the rapid solidification rate of the molten metal. It is easy to form brittle structures in the HAZ of HSLA welds and cause a high value of residual stress [14]. However, scholars have also invented several methods to improve weldability in the water environment. Zhang et al. [15] employed a real-time induction heating-assisted process to reduce the cooling rate of joints in the underwater environment and improve the mechanical properties. During underwater welding processing, an ultrasonic wave was used to control the dynamic bubble and improve the arc stability [16]. The ultrasonic wave could also reduce the porosity and reduce the diffusible hydrogen content in the deposited metal [17]. Tomków et al. reported that changing the sequence of the beads during the process could reduce the susceptibility of steel to cold cracking [18]. The additional welded stitches laid on the face of the welded joint could provide an in situ local heat treatment, which could temper the brittle structures in the HAZ and reduce the hardness in this area [12]. Post-weld heat treatment could also be used to improve the mechanical properties $[19,20]$.

Compared to UWW and ULCW, the cooling rate of UDW is slower. And UDW can avoid the disadvantages of the water environment. To obtain welds with good quality, we use underwater dry gas metal arc welding (GMAW) to complete the repair of the HSLA. The pressure in the chamber is an important parameter for the UDW process. Firstly, it can affect the cooling rate, which has an impact on the microstructure evolution and mechanical properties of welds. The cooling time of the weld pool decreases with increasing pressure because of the higher chamber gas density [21]. Secondly, the pressure could also affect the solidification process of the weld metal because the high pressure could not only make the arc contract, but also affect the arc instability and the droplet transfer frequency [22]. The high pressure could also increase the penetration depth of the arc and enhance the melt flow magnitude (faster) and direction (inward) [23].

Thus, the present work aims to study how different water depths affect the microstructure evolution and mechanical properties of underwater dry weld metal of high strength steel Q690E. The present work will make a significant contribution to the UDW of HSLA.

\section{EXPERIMENTAL MATERIALS AND PROCEDURE}

The base material (BM) is Q690E HSLA steel (690 indicating that the minimum value of yield strength is 690 $\mathrm{MPa})$. Workpieces of Q690E steel $(300 \times 100 \times 10 \mathrm{~mm})$ were prepared. The detail of the groove is shown in Fig. 1 . The schematic illustration of the GMAW joint is shown in Fig. 2. The filler metal was EASB solid-core wire Mn3Ni1CrMo with a diameter of $1.2 \mathrm{~mm}$. Table 1 presents the chemical compositions (by wt.\%) of the Q690E HSLA steel and filler wire based on the manufacturer data. An automatic UDW system located in a hyperbaric chamber is used to carry out the underwater dry welding experiment. The underwater welding system consists of a hyperbaric chamber, threedimensional motion platform, welding power source, welding torch, wire feeding machine, and auxiliary equipment. Before UDW, the chamber is filled with compressed air, which is used to simulate the pressure associated with the water depth (the water depth of $10 \mathrm{~m}$ can be simulated by compressed air with $0.1 \mathrm{MPa}$ ) [24]. Formula (1) presents the calculation method of the carbon equivalent based on the International Institute of Welding equation (CEIIW) [25].

$$
C_{I I W}=C+\frac{M n}{6}+\frac{(C r+M o+V)}{5}+\frac{(N i+C u)}{15}
$$

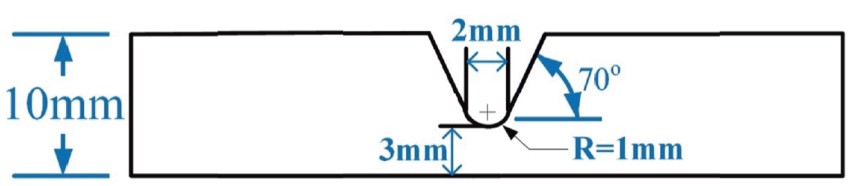

Fig. 1. Cross-section profile of the joint groove.

During UDW, there was no water in the high-pressure chamber but the UDW processes were conducted at three different pressures $(0,0.2$, and $0.4 \mathrm{MPa})$, which are equivalent to different water depths $(0,20$, and $40 \mathrm{~m})$. The shielding gas

Table 1. Chemical compositions of the Q690E HSLA steel and Mn3Ni1CrMo filler wire (wt. \%).

\begin{tabular}{|c|c|c|c|c|c|c|c|c|c|c|c|c|c|c|c|}
\hline & $\mathrm{C}$ & $\mathrm{Si}$ & $\mathrm{Mn}$ & $\mathrm{P}$ & S & $\mathrm{Cr}$ & $\mathrm{Ni}$ & $\mathrm{Al}$ & $\mathrm{Ti}$ & $\mathrm{Nb}$ & Mo & V & $\mathrm{Cu}$ & $\mathrm{Fe}$ & $\mathrm{CE}_{\text {III }}$ \\
\hline Q690E & 0.14 & 0.19 & 1.03 & 0.009 & 0.004 & 0.57 & 0.45 & 0.048 & 0.015 & 0.034 & 0.26 & - & - & Bal. & 0.51 \\
\hline $\mathrm{Mn}_{3} \mathrm{Ni}_{1} \mathrm{CrMo}$ & 0.06 & 0.6 & 1.6 & 0.01 & 0.01 & 0.3 & 1.4 & - & - & - & 0.25 & 0.07 & 0.07 & Bal. & 0.55 \\
\hline
\end{tabular}


was $80 \% \mathrm{Ar} 2+20 \% \mathrm{CO} 2$. The UDW parameters and heat inputs are listed in Table 2. Formula (2) presents the calculation method of the heat input.

$$
q=\eta U I / v
$$

In this formula, $\mathrm{q}$ is the heat input $(\mathrm{kJ}), \mathrm{I}$ is the welding current (A), $\mathrm{U}$ is the arc voltage $(\mathrm{V}), v$ is the welding speed (mm.s-1), and $\eta$ is the arc efficiency. For GMAW, $=0.85$ [26].

The microstructure was characterised using an optical microscope (OM). The crystallographic features and grain size of ferrites within the welds were observed by using a scanning electron microscope (SEM) equipped with an electron backscattered diffraction (EBSD) system. To evaluate the mechanical properties of the welds, tensile test specimens were subjected to tensile testing. The location of the test specimen in the welds is shown in Fig. 2. The dimensions of all tensile specimens were designed following ASTM E8M16a [27] (as shown in Fig. 2). After the tensile tests, SEM was used to observe the fracture surfaces.

Table 2. UDW parameters and heat inputs.

\begin{tabular}{|c|c|c|c|c|c|c|}
\hline $\begin{array}{c}\text { Specimen } \\
\text { No. }\end{array}$ & 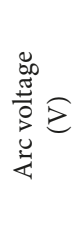 & 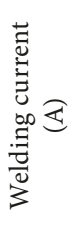 & 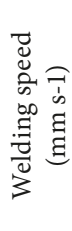 & 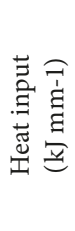 & 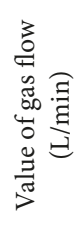 & 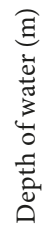 \\
\hline UDW-0 & 26 & 220 & 4 & 1.216 & $25-30$ & 0 \\
\hline UDW-20 & 26 & 220 & 4 & 1.216 & $25-30$ & 20 \\
\hline UDW-40 & 26 & 220 & 4 & 1.216 & $25-30$ & 40 \\
\hline
\end{tabular}

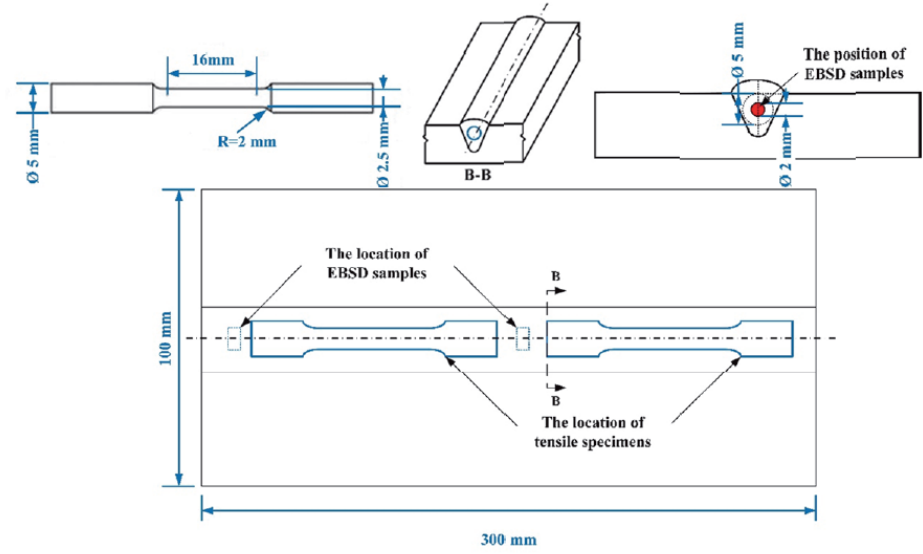

Fig. 2. Schematic illustrations of tested samples.

\section{RESULTS AND DISCUSSION}

\section{MICROSCOPIC TESTING}

Fig. 3 shows the microstructure of the weld metals (WM), which are dominated by acicular ferrite (AF). Also, parts of proeutectoid ferrite (PF) and ferrite side plate (FSP) are found. From Fig. 3, the volume fraction of AF in UDW-40 and UDW-20 is higher than in the weld conducted at a lower pressure $(0 \mathrm{MPa})$, although the percentage of $\mathrm{PF}$ decreases. Fig. 4 summarises the grain size of the ferrites from the whole scanning areas of the three UDW joints. From the statistical distribution of the crystallographic grain size (Fig. 4), it is easy to find that the frequency of fine ferrite in the WM of UDW-40 and UDW-20 is higher than that of UDW-0. The WM completed under higher ambient pressure shows more ferrite with larger grain sizes because of the different cooling rates caused by different welding pressures. The cooling time of the weld pool decreases with increasing pressure. The high pressure results in high gas density and high thermal conductivity [21]. Also, the high pressure harms the arc stability. The arc efficiency factor is relatively low at high pressure because more welding powder is needed to hold the arc rather than transfer to the molten pool [28]. Farrell [29] explored the cooling time through the temperature range of $1200-800^{\circ} \mathrm{C}$ under different water depths when he studied the UDW of duplex stainless steel offshore pipelines. He reported that the time decreased gradually with increasing water depth (5.2 s for $10 \mathrm{~m}, 5.08 \mathrm{~s}$ for $40 \mathrm{~m}, 4.3 \mathrm{~s}$ for $160 \mathrm{~m}$, and $3.2 \mathrm{~s}$ for $320 \mathrm{~m}$ ) [29].

Thus, the cooling rate of the UDW joint increases when the ambient pressure increases from 0 to $40 \mathrm{MPa}$. Many researchers agreed that [30] the increasing cooling rate could result in a decrease of the bainite transformation start temperature, an improvement of the thermodynamic driving force for nucleation, and the growth of AF laths. Hence, the weld metal of UDW-40 shows more AF. The lath of parts of AF also increases. At the same time, Babu [31] found that the external stress could provide a mechanical driving force for AF transformation and improve the selection of a particular growth variant among the 12 different Nishiyama-Wasserman (NW) or 24 different Kurdjumov-Sachs (KS) orientation relationships. The stress during transformation could destroy the conventional AF in which the plates emanating from inclusions point in different directions and improve the development of the specific crystallographic variants. During underwater dry welding, the solidification process of the liquid weld pool is affected by the ambient pressure from all directions. Thus, there is no clear alignment of acicular ferrite plates within underwater dry welds, and the lath of acicular ferrite increases with increasing ambient pressure. 

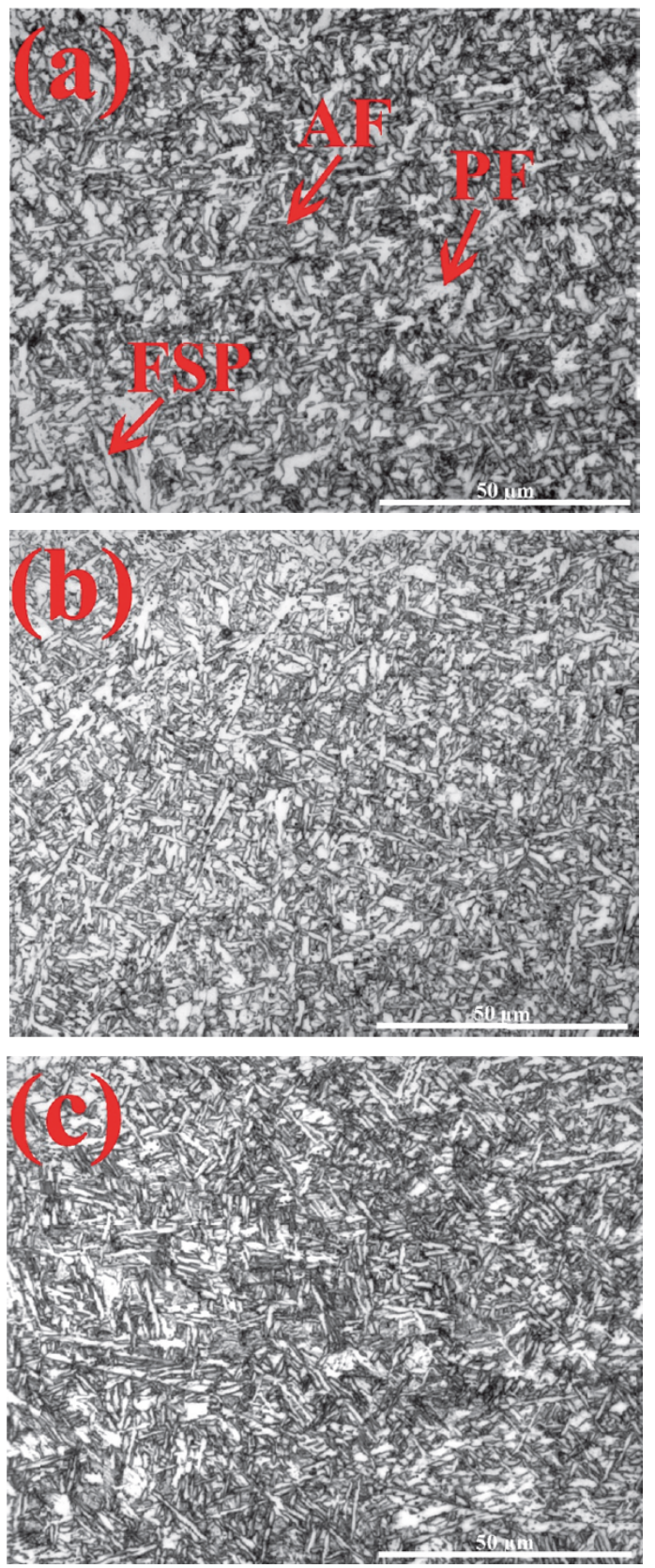

Fig. 3. Optical microstructures of the central weld metals: (a) UDW-0; (b) $U D W-20$; (c) UDW-40.

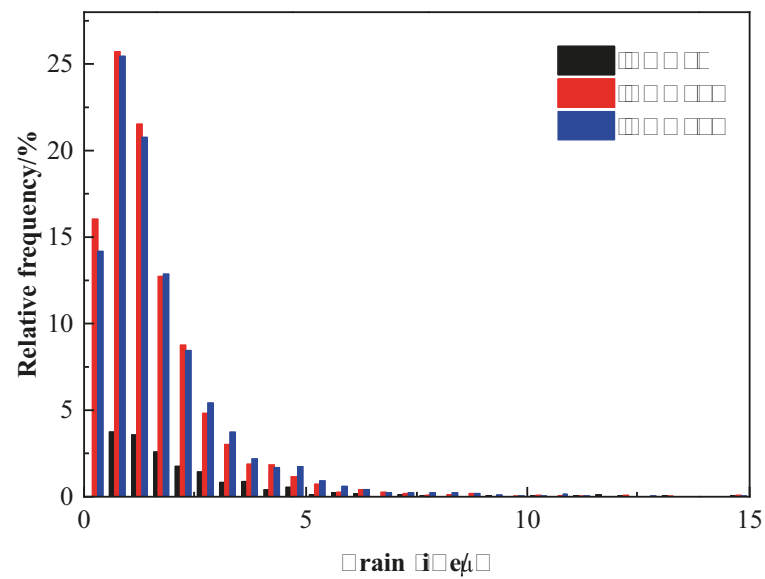

Fig. 4. The crystallographic grain size of ferrites from the three WMs.
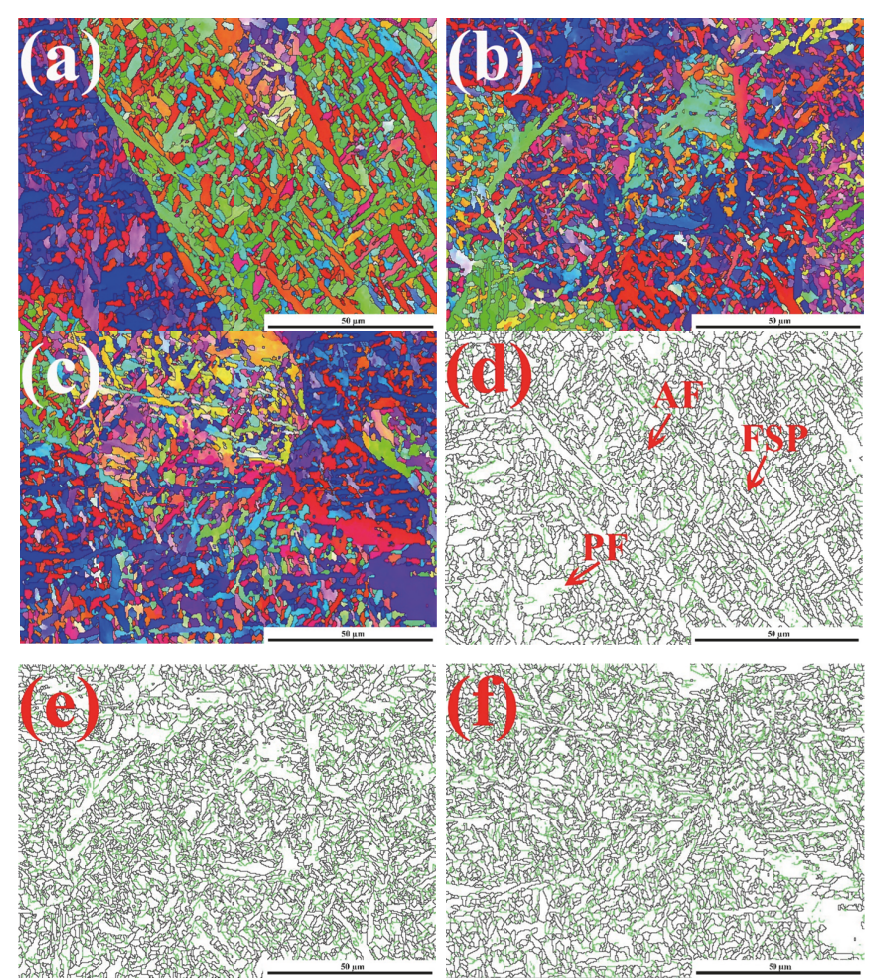

Fig. 5. Inverse pole figure and band contrast maps showing the morphology of ferrite structures and the boundaries distribution with weld metals completed under different ambient pressure: $(a, d)$ ambient pressure $=0 \mathrm{MPa} ;(b, e)$ ambient pressure $=0.2 \mathrm{MPa} ;(c, f)$ ambient pressure $=0.4 \mathrm{MPa}$.

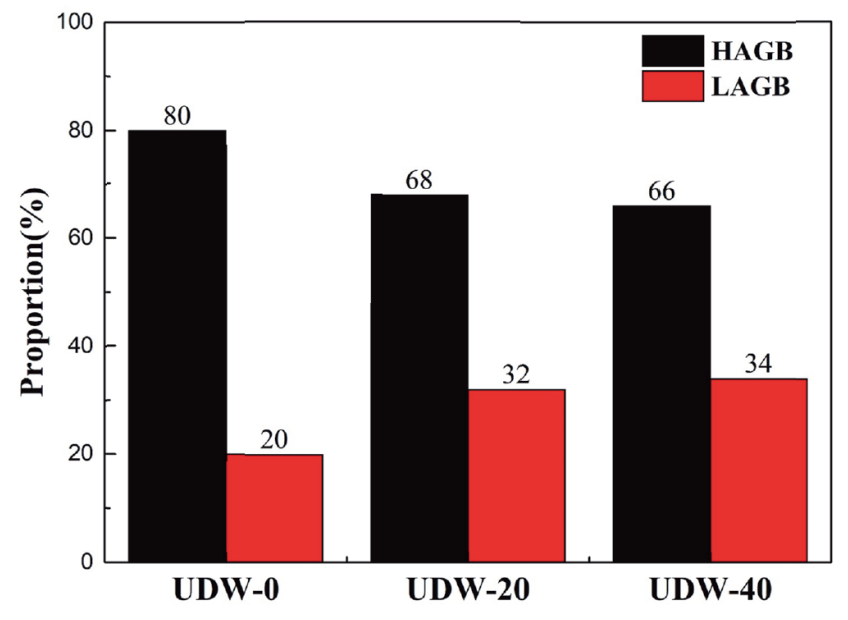

Fig. 6. The proportion of grain boundaries with different angles for WMs (HAGB: high-angle grain boundaries; LAGB: low-angle grain boundaries).

Fig. 5 shows the EBSD inverse pole figure (IPF) and band contrast (BC) maps of the WMs. In Fig. 5 d, e, and $\mathrm{f}$, low-angle grain boundaries (LAGB) are represented by green lines, and high-angle grain boundaries (HAGB) are represented by black lines (LAGB: $2^{\circ}<\theta<15^{\circ}$; HAGB: $\theta$ $>15^{\circ} ; \theta$ - misorientation). The colours in Fig. 5 a,b, and c correspond to the crystallographic orientation. They clearly show the detailed morphology and crystallographic features of the ferrite structure. These figures indicate that three different ferrite structures (AF, PF, and FSP) and the AF 
grains present various directions and show different colours from those of neighbouring ferrites. From Fig. 5 d,e, f, and Fig. 6 , the density of HAGB in the WM of UDW decreases with decreasing underwater welding pressure, while the density of LAGB increases. Young Min Kim et al. [32] investigated the microstructural characteristics of AF and they found that an AF grain consists of several sub-units misoriented by $1-2^{\circ}$, a number of the boundaries between AF grains exhibit misorientation angles of $5-10^{\circ}$, and that lots of adjacent $\mathrm{AF}$ grains with misorientation below $15^{\circ}$ make up the crystallographic packet.

\section{MECHANICAL PROPERTIES}

Six representative tensile stress-displacement curves of WMs are shown in Fig. 7. The tensile properties of the WMs, yield strength (YS) and ultimate tensile strength (UTS) are summarised in Table 3. From Fig. 7 and Table 3, the UDW-40 specimen presents good YS and UTS. The YS and UTS of the UDW-40 specimen (750.6 $\mathrm{MPa}$ and $920.91 \mathrm{MPa})$ are higher than those of the UDW-20 specimen (YS: 710.6 MPa, UTS: 866.235 MPa). Also, the YS (678.69 MPa) and UTS $(810.075 \mathrm{MPa})$ of the UDW-0 specimen are $72 \mathrm{MPa}$ and $\sim 110 \mathrm{MPa}$ lower than those of the UDW-40 specimen. The dislocations with high density and the AF with fine grains result in good strength and toughness [32]. From Fig. 3 and Fig. 4, the proportion of fine AF in UDW-40 and UDW-20 is higher than UDW-0, but the percentage of PF and FSP decreases with the increasing water depth. Fig. 4 shows that the frequency of fine ferrite in WM of UDW-40 is higher than that in WM of UDW-0 and UDW-20. The mechanical properties of the weld metals could be improved by grain refinement of AF, which increases the amount and density of dislocation, and improves the uniform distribution [33]. Also, the fine grain size is important for improving the tensile properties [32]. As the underwater welding pressure and the cooling rate increase, the effective grain is refined, and the dislocation density increases, which improves the tensile properties of the WM. The increasing AF and grain refinement improve the tensile properties [33]. From Fig. 5 and Fig. 6, the density of LAGB within the weld metals increases dramatically and improves the tensile properties. The grains with low misorientation $\left(2^{\circ}<\theta<15^{\circ}\right)$ are one of the factors that affect the strength because LAGB contributes to the dislocation strengthening [34]. The increasing underwater pressure and cooling rate result in raising of the proportion of LAGB (Fig. 6), which contributes to the refinement of AF substructures and a notable increase of the tensile properties through boundary strengthening.

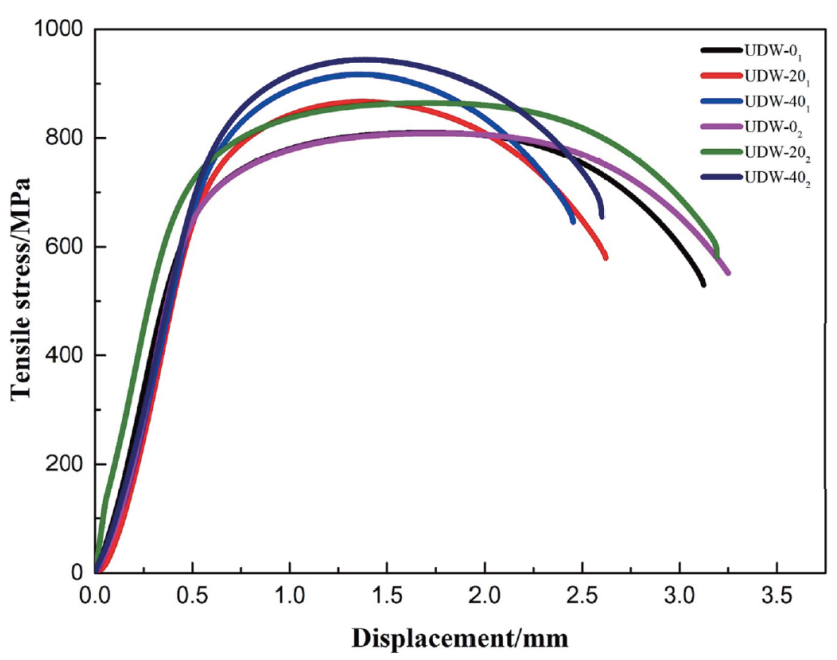

Fig. 7. Tensile stress-displacement curves of the three welds.
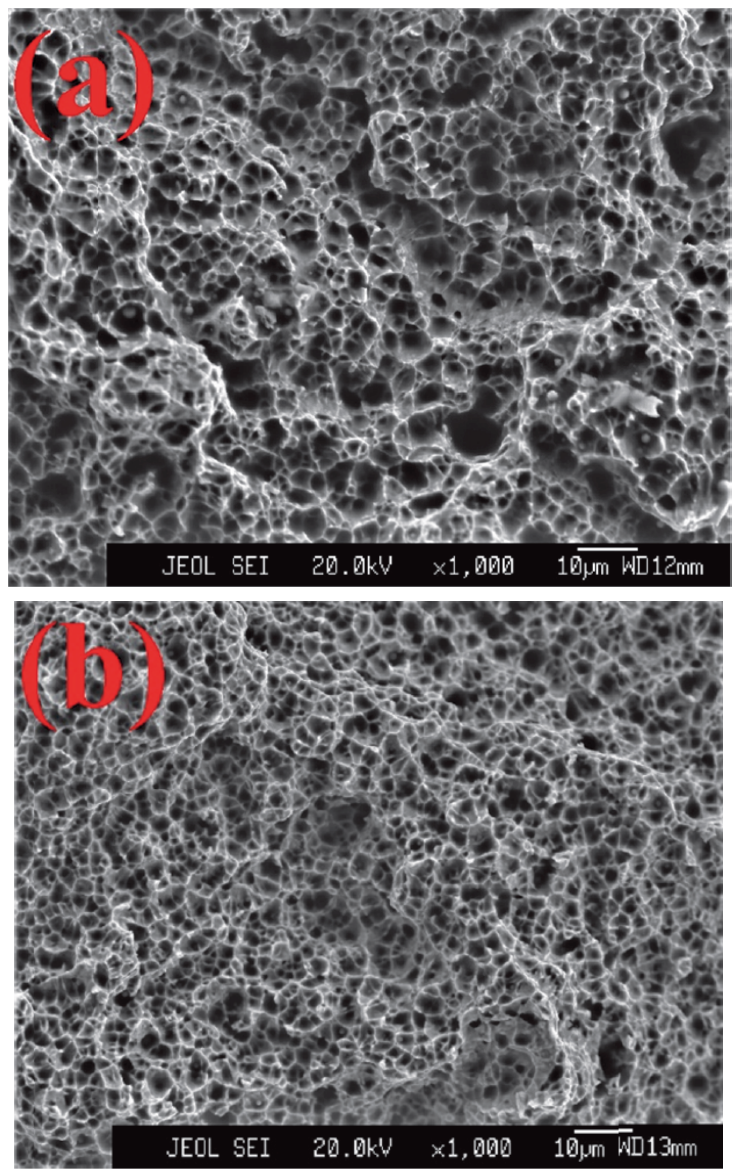

Table 3. Tensile properties for the three weld metals.

\begin{tabular}{|c|c|c|c|c|c|c|c|c|}
\hline Test specimen & $\begin{array}{c}\text { Yield } \\
\text { strength Test } \\
1(\mathrm{MPa}) \\
\end{array}$ & $\begin{array}{l}\text { Yield strength } \\
\text { Test } 2(\mathrm{MPa})\end{array}$ & $\begin{array}{l}\text { Average yield } \\
\text { strength (MPa) }\end{array}$ & $\begin{array}{l}\text { Standard } \\
\text { deviation }\end{array}$ & $\begin{array}{c}\text { Tensile } \\
\text { strength } \\
\text { Test } 1(\mathrm{MPa})\end{array}$ & $\begin{array}{c}\text { Tensile } \\
\text { strength } \\
\text { Test } 2(\mathrm{MPa})\end{array}$ & $\begin{array}{c}\text { Average tensile } \\
\text { strength } \\
(\mathrm{MPa})\end{array}$ & $\begin{array}{l}\text { Standard } \\
\text { deviation }\end{array}$ \\
\hline UDW-0 & 706 & 688 & 697 & 9 & 846 & 847 & 846.5 & 0.5 \\
\hline UDW-20 & 750 & 744 & 747 & 3 & 904 & 901 & 902.5 & 1.5 \\
\hline UDW-40 & 783 & 791 & 787 & 4 & 954 & 961 & 957.5 & 3.5 \\
\hline
\end{tabular}




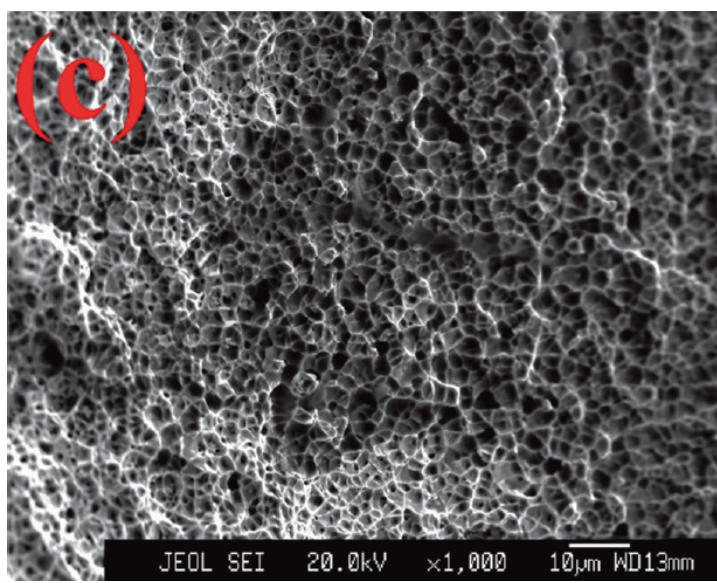

Fig. 8. The fracture surface morphology for the tensile test specimens: (a) $U D W-0$; (b) UDW-20; (c) UDW-40.

SEM was used to identify the fracture mechanism of the three tensile test specimens. Fig. 8 shows the fracture surfaces of these specimens. The fracture mechanism of all specimens is quasi-cleavage because cleavage facets and dimples of various sizes and depths were observed in the tensile fracture surface of all samples.

Compared with the microstructure of other kinds of underwater welded joints $[13,35]$, the microstructure of UDW Q690E HSLA joints does not show any slags, pores, and microcracks. Also, the weld metal completed below $40 \mathrm{~m}$ shows the best mechanical properties. The high pressure of 0.4 $\mathrm{MPa}$ has a more positive effect on the mechanical properties of the WM compared with $0.2 \mathrm{MPa}$ and $0 \mathrm{MPa}$.

\section{CONCLUSIONS}

In the present study, Q690E HSLA steel plates are welded by UDW at different water depths. The microstructure evolution and mechanical properties of the welds are studied. The following conclusions are reached:

1. The volume fraction of AF in UDW joints increased with the increasing depth of the water. And with a decrease in UDW pressure, the density of HAGB in the WM did not increase significantly, but the density of LAGB decreased dramatically from $34 \%$ for UDW- 40 to $20 \%$ for UDW- 0 .

2. More fine ferrites and the increasing low-angle boundaries improve the strength of the WM of UDW-40 (YS: 787 $\mathrm{MPa}$, TS: $957.5 \mathrm{MPa}$ ) because they impede the dislocation movement.

\section{ACKNOWLEDGEMENTS}

The authors gratefully acknowledge the financial help rendered by the National Natural Science Foundation of China (Grant No. 51374111) and the Natural Science Foundation of Guangdong Province (Grant No. 2020A1515011050) in supporting this work.

\section{REFERENCES}

1. J. Łabanowski, "Development of under-water welding techniques", Welding International, vol. 25, no. 12, pp. 933-937, 2011.

2. M. Rowe and S. Liu, "Recent developments in underwater wet welding", Science and Technology of Welding and Joining, vol. 6, no. 6, pp. 387-396, 2001.

3. Y. Shi et al., "Microstructure evolution and mechanical properties of underwater dry and local dry cavity welded joints of $690 \mathrm{MPa}$ grade high strength steel”, Materials, vol. 11, no. 1, p. 167, 2018.

4. S. Godwin Barnabas, S. Rajakarunakaran, G. Satish Pandian, A. Muhamed Ismail Buhari, and V. Muralidharan, "Review on enhancement techniques necessary for the improvement of underwater welding", Materials Today: Proceedings, 2020.

5. N. Guo, Y. Fu, X. Xing, Y. Liu, S. Zhao, and J. Feng, "Underwater local dry cavity laser welding of 304 stainless steel”, Journal of Materials Processing Technology, vol. 260, pp. 146-155, 2018.

6. J. Tomków, J. Łabanowski, D. Fydrych, G. Rogalski, "Cold cracking of S460N steel welded in water environment", (in English), Polish Maritime Research, vol. 25, no. 3, pp. 131-136, 01 Sep. 2018.

7. C. J. Bayley and A. Mantei, "Influence of weld heat input on the fracture and metallurgy of HSLA-65", Canadian Metallurgical Quarterly, vol. 48, no. 3, pp. 311-316, 2009.

8. C. Pandey, M. M. Mahapatra, P. Kumar, F. Daniel, and B. Adhithan, "Softening mechanism of P91 steel weldments using heat treatments", Archives of Civil and Mechanical Engineering, vol. 19, no. 2, pp. 297-310, 2019.

9. C. L. Davis and J. E. King, "Effect of cooling rate on intercritically reheated microstructure and toughness in high strength low alloy steel", Materials Science and Technology, vol. 9, no. 1, pp. 8-15, 1993.

10. A. Lambert, A. Lambert, J. Drillet, A. F. Gourgues, T. Sturel, and A. Pineau, "Microstructure of martensite-austenite constituents in heat affected zones of high strength low alloy steel welds in relation to toughness properties", Science and Technology of Welding and Joining, vol. 5, no. 3, pp. 168-173, 2000.

11. D. M. Viano, N. U. Ahmed, and G. O. Schumann, "Influence of heat input and travel speed on microstructure and mechanical properties of double tandem submerged arc high strength low alloy steel weldments", Science and Technology of Welding and Joining, vol. 5, no. 1, pp. 26-34, 2000 . 
12. J. Tomków and A. Janeczek, "Underwater in situ local heat treatment by additional stitches for improving the weldability of steel", Applied Sciences, vol. 10, no. 5, 2020.

13. H. Chen, N. Guo, C. Liu, X. Zhang, C. Xu, and G. Wang, "Insight into hydrostatic pressure effects on diffusible hydrogen content in wet welding joints using in-situ X-ray imaging method", International Journal of Hydrogen Energy, vol. 45, no. 16, pp. 10219-10226, 2020.

14. J. Tomków, D. Fydrych, G. Rogalski, and J. Łabanowski, "Temper bead welding of S460N steel in wet welding conditions", Advances in Materials Science, vol. 18, no. 3, pp. 5-14, 01 Sep. 2018.

15. H. Zhang, X. Dai, J. Feng, and L. L. Hu, "Preliminary investigation on real-time induction heating-assisted underwater wet welding", vol. 1, pp. 8-15, 2015.

16. J. Wang, Q. Sun, T. Zhang, X. Tao, P. Jin, and J. Feng, "Arc stability indexes evaluation of ultrasonic wave-assisted underwater FCAW using electrical signal analysis", The International Journal of Advanced Manufacturing Technology, vol. 103, no. 5, pp. 2593-2608, 2019.

17. H. Chen, N. Guo, K. Xu, C. Xu, L. Zhou, and G. Wang, "In-situ observations of melt degassing and hydrogen removal enhanced by ultrasonics in underwater wet welding”, Materials \& Design, vol. 188, p. 108482, 2020.

18. J. Tomków, D. Fydrych, and G. Rogalski, "Role of bead sequence in underwater welding", Materials, vol. 12, no. 20, 2019.

19. C. Pandey, M. M. Mahapatra, P. Kumar, N. Saini, and A. Srivastava, "Microstructure and mechanical property relationship for different heat treatment and hydrogen level in multi-pass welded P91 steel joint”, Journal of Manufacturing Processes, vol. 28, pp. 220-234, 2017.

20. C. Pandey, M. M. Mahapatra, P. Kumar, and S. Sirohi, "Fracture behaviour of crept P91 welded sample for different post weld heat treatments condition", Engineering Failure Analysis, vol. 95, pp. 18-29, 2019.

21. U. Ofem, S. Ganguly, S. Williams, and N. Woodward, "Investigation of thermal cycle and metallurgical characteristics of hyperbaric gas metal arc welding", International Journal of Offshore and Polar Engineering, vol. 24, no. 03, pp. 206-212, 2014.

22. J. Huang, L. Xue, J. Huang, Y. Zou, H. Niu, and D. Tang, "Arc behavior and joints performance of CMT welding process in hyperbaric atmosphere", Acta Metall Sin, vol. 52, no. 1, pp. 93-99, 2015.
23. I. Bunaziv, R. Aune, V. Olden, and O. M. Akselsen, "Dry hyperbaric welding of HSLA steel up to 35 bar ambient pressure with CMT arc mode", The International Journal of Advanced Manufacturing Technology, vol. 105, no. 5, pp. 2659-2676, 2019.

24. Y. Hu, Y. Shi, K. Sun, and X. Shen, "Microstructure evolution and mechanical performance of underwater local dry welded DSS metals at various simulated water depths", Journal of Materials Processing Technology, vol. 264, pp. 366-376, 2019.

25. V. B. Ginzburg and R. Ballas, Flat rolling fundamentals. CRC Press, 2000.

26. S. Kou, Welding Metallurgy, 2nd ed. Hoboken: JohnWiley \& Sons, 2003; pp. 37-42.

27. ASTM E8 / E8M-16ae1, Standard Test Methods for Tension Testing of Metallic Materials, ASTM International, West Conshohocken, PA, 2016, Available: http://www.astm.org.

28. A. S. Azar, N. Woodward, H. Fostervoll, and O. M. Akselsen, "Statistical analysis of the arc behavior in dry hyperbaric GMA welding from 1 to 250 bar", Journal of Materials Processing Technology, vol. 212, no. 1, pp. 211$219,2012$.

29. J. Farrell, "Hyperbaric welding of duplex stainless steel pipelines offshore", Cranfield University, 1996.

30. I. A. Yakubtsov, P. Poruks, and J. D. Boyd, "Microstructure and mechanical properties of bainitic low carbon high strength plate steels", Materials Science and Engineering: A, vol. 480, no. 1, pp. 109-116, 2008.

31. S. S. Babu, "Acicular ferrite and bainite in $\mathrm{Fe}-\mathrm{Cr}-\mathrm{C}$ weld deposits", University of Cambridge, 1992.

32. Y. M. Kim, H. Lee, and N. J. Kim, "Transformation behavior and microstructural characteristics of acicular ferrite in linepipe steels", Materials Science and Engineering: A, vol. 478, no. 1, pp. 361-370, 2008.

33. M. Fattahi, N. Nabhani, M. Hosseini, N. Arabian, and E. Rahimi, "Effect of Ti-containing inclusions on the nucleation of acicular ferrite and mechanical properties of multipass weld metals", Micron, vol. 45, pp. 107-114, 2013.

34. I. Gutiérrez, "Effect of microstructure on the impact toughness of Nb-microalloyed steel: Generalisation of existing relations from ferrite-pearlite to high strength microstructures", Materials Science and Engineering: A, vol. 571, pp. 57-67, 2013. 
35. G. Terán, S. Capula-Colindres, D. Angeles-Herrera, J. C. Velázquez, and M. J. Fernández-Cueto, "Estimation of fracture toughness KIC from Charpy impact test data in T-welded connections repaired by grinding and wet welding”, Engineering Fracture Mechanics, vol. 153, pp. 351-359, 2016.

\title{
CONTACT WITH THE AUTHORS
}

\author{
Yonghua Shi \\ e-mail:yhuashi@scut.edu.cn
}

School of Mechanical and Automotive Engineering

South China University of Technology

Guangzhou 510640

Guangdong Provincial Engineering Research Center for Special Welding Technology and Equipment

South China University of Technology

Guangzhou 510640

China 